\title{
Jesus, a pecadora e o fariseu. Uma releitura na ótica de Gênero
}

Tereza Maria Pompéia Cavalcanti

\section{Introdução}

Neste momento de início de um novo século e milênio, vivemos o desafio de redefinição de nossa identidade enquanto seres humanos situados numa sociedade sujeita a mudanças rápidas e profundas. São transformações que atingem nosso cotidiano, nossos hábitos em relação a nossos corpos, gestos, raciocínios, crenças e padrões de comportamento. Somos atingidos/as especialmente em nossas relações com nossos semelhantes, com a natureza e com Deus.

Uma forma de buscar critérios para a redefinição de nossa identidade é reler a Bíblia a partir do acontecimento e da pessoa de Jesus Cristo, que se tornou para nós a grande chave de interpretação da Bíblia e da própria vida. Reler a Bíblia sempre com novas perguntas, entre elas a pergunta sobre as relações de gênero, é um exercício que sempre traz surpresas e boas novas.

Sendo assim, por trás de toda essa reflexão está o desejo de lançar um olhar sobre a Bíblia, enquanto fonte e referencial básico de nossa fé. O olhar crítico da ciência nos adverte contra possíveis equívocos e preconceitos que a "construção social da realidade" modelou em nós, particularmente no que toca

\footnotetext{
1 A construção social da realidade é um conceito largamente utilizado pela sociologia e pela abordagem de gênero. Ver BERGER, Peter L.; LUCKMANN, Thomas, A construção social da realidade: tratado de sociologia do conhecimento. Petrópolis, Vozes, 1993. Lembro que a idéia de "construção social" indica aquilo que não pertence à natureza das coisas (e portanto
} 
aos padrões de "masculino" e "feminino". Munidos/as, portanto, dessa visão crítica da ciência, dirigimos à Bíblia novas perguntas e, desta forma, iluminamos aspectos dos textos que tinham passado despercebidos ou permanecido ocultos. Projetamos na Escritura uma luz nova e, em resposta, ela deixa emergir seu brilho que por sua vez vai iluminar os recantos obscuros da nossa vida.

Creio que há como que uma reciprocidade entre:

- o foco de luz com que iluminamos os textos a partir da vida e

- o farol com que os mesmos textos nos iluminam a partir da fé.

Nessa perspectiva, retomamos aqui um artigo publicado na revista Estudos Bíblicos 24, 1989, 32-53, com algumas modificações, visando ilustrar a abordagem de gênero aplicada sobre um texto específico. Assim, para experimentarmos o "sabor" da hermenêutica bíblica na perspectiva de gênero, vamos propor a leitura do texto de Lc 7,36-50. Será uma leitura e interpretação bem esquemática, dados os limites desta contribuição.

Antes de ir ao texto, quero deixar claros alguns pressupostos deste exercício. Suponho que o público a quem me dirijo já conhece basicamente o contexto sócio-cultural da Palestina no tempo de Jesus e das primeiras comunidades cristãs. Suponho também conhecida, em suas grandes linhas, a obra de Lucas $\left(3^{\circ}\right.$. Evangelho e Atos dos Apóstolos), as principais características do autor e os problemas das comunidades a quem ele se dirigiu em primeira instância. Finalmente, imagino que os leitores deste texto já possuem uma certa familiaridade com as questões novas que nosso contexto de hoje levanta aos escritos bíblicos. No caso desta abordagem, vamos nos restringir ao novo que parece emergir do texto quando iluminado a partir da ótica de gênero ${ }^{2}$. E guardamos uma perspectiva pastoral, utilizando uma linguagem simples, direta, sem nos alongarmos com referências exegéticas.

Feitas essas considerações, vamos caminhar em três passos:

Primeiro, vamos desenvolver algumas observações sobre o contexto literário imediato da perícope de Lc 7,36-50. Num segundo momento, veremos alguns aspectos do contexto sócio-cultural e religioso da época de Jesus e das primeiras comunidades cristãs. Finalmente, no terceiro passo, abordaremos a atitude das três personagens envolvidas no texto.

não é imutável), mas que é estabelecido arbitrariamente pelos seres humanos organizados em sociedade, de acordo com os interesses de determinados grupos.

${ }^{2}$ Para uma rápida introdução a essa temática, ver BRANDÃO, Margarida L., "Gênero e experiência de mulheres" em: ANJOS, Márcio Fabri dos, Teologia aberta ao futuro, São Paulo, SOTER/Loyola, 155-165. 
Há dois dados importantes no que se refere ao contexto literário imediato da perícope de Lc 7,36-50:

1) O texto é precedido da frase: "Mas a Sabedoria é justificada por todos os seus filhos" (Lc 7,35). Esta frase, que tem um paralelo em Mt 11,193 , é uma resposta de Jesus que encerra toda uma discussão sobre a dificuldade de as pessoas reconhecerem os profetas de seu tempo (cf. Lc 7,33-34). A menção à Sabedoria aqui é importante porque ela representa um tema frequente, desde a volta do exílio, quando uma corrente do judaísmo colocava novas questões à tradição de Israel diante da cultura helenista. Tal corrente alternativa (onde certamente as mulheres tiveram seu papel) simboliza a Sabedoria na figura de uma mulher presente junto a Deus desde os primórdios da criação (cf. Pr 8,22-31) e que se oferece aos seres humanos como um dom precioso, um verdadeiro banquete (cf. Pr 9,1-5; Eclo 24,19-21) ${ }^{4}$. Em Pr 8,32ss, a Sabedoria fala:

"Portanto, meus filhos, escutai-me: felizes os que guardam
meus caminhos! Escutai a disciplina e tornai-vos sábios,
não a desprezeis. Feliz o homem que me escuta, velando
em minhas portas a cada dia, guardando os batentes da
minha porta! Quem me encontra, encontra a vida, e goza
do favor de Iahweh!"

Ora, o Novo Testamento apresenta em diversas passagens Jesus assumindo para si essa figura da Sabedoria divina ${ }^{5}$. E não é por simples acaso que Lc situa o texto que nos ocupa exatamente aqui, ligado com essa problemática da Sabedoria. Na realidade o episódio narrado em Lc 7,36-50 pode ser considerado um comentário da frase de Lc 7,35, ou uma ilustração da temática de ser sábio ou ser insensato ${ }^{6}$.

\footnotetext{
${ }^{3}$ Em Mt lê-se "suas obras" em lugar de "seus filhos". Ver comentário sobre esse versículo na Bíblia de Jerusalém, nota $u$.

${ }^{4} \mathrm{Cf}$. as interessantes observações de Mercedes LOPES sobre esse contexto cultural em $A$ confissão de Marta. Leitura a partir de uma ótica de gênero. São Paulo, Paulinas, 1996, 15-18. Ver, da mesma autora, A mulher sábia e a sabedoria mulher. São Leopoldo, Oikos, 2007.

${ }^{5}$ Cf. Mt 11,28-30; 12,42; 23,34p; Jo 6,35, etc.

${ }^{6}$ Cf. CAVALCANTI, T., "Jesus, the Penitent woman and the Pharisee", em: Journal of hispanic/Latino Theology, v. 2, n. 1, 1994, 31. KONINGS, J., Espírito e mensagem: Liturgia dominical. Petrópolis, Vozes, 1981.
} 
2) Ao texto de Lc 7,36-50 segue-se um sumário sobre a atividade de Jesus, no qual aparecem os seus seguidores e seguidoras mais próximas: os Doze, mais uma lista de mulheres que haviam sido curadas por Jesus:

\begin{abstract}
"Maria, chamada Madalena, da qual haviam saido sete demônios; Joana, mulher de Cuza, administrador de Herodes; Susana e várias outras que os atendiam com seus bens." (Lc 8,2-3)
\end{abstract}

Observemos que aqui várias mulheres são nomeadas e identificadas, o que não acontece na lista de At 1,14, onde provavelmente as mesmas mulheres estavam presentes, mas somente figura o nome de Maria, mãe de Jesus. Será que no período da redação do livro dos Atos já não interessava mais ao autor - o mesmo de Lc - nomear as mulheres ${ }^{7}$ ?

Conclui-se, portanto, que o contexto literário mais imediato da nossa perícope funciona como uma moldura onde a presença da mulher e do feminino é evidenciada e ressaltada. Isto denota a importância do papel das mulheres e do feminino no momento crucial das origens do cristianismo: o momento de reconhecer em Jesus o Profeta e Mensageiro de Deus, e a própria Sabedoria de Deus encarnada.

B) Observações sobre o contexto sócio-cultural e religioso da época.

Referimo-nos aqui particularmente aos aspectos envolvidos no texto de Lc 7,36-50.

Notam-se os seguintes aspectos do texto:

1) A abordagem de gênero chama atenção sobre as idéias socialmente construídas a respeito dos grupos e das pessoas dentro da sociedade ${ }^{8}$. Não há dúvida de que a Lei e as tradições religiosas na sociedade judaica no tempo de Jesus, e também no tempo em que Lucas redige sua obra, colocavam o homem numa posição superior à da mulher. Assim, pelo simples fato de nascer homem ou mulher, a pessoa já tinha decretada sua superioridade ou inferioridade na vida social e religiosa. Ana Maria TEPEDINO faz uma lista de discriminações a que a mulher era sujeita naquela socie-

\footnotetext{
${ }^{7}$ Ver sobre isto REIMER, Ivone R., Vida de mulheres na sociedade e na Igreja. São Paulo, Paulinas, 1995, 15-16. Sobre o anonimato das mulheres na Bíblia, a obra clássica é de FIORENZA, Elisabeth Schussler, As origens cristãs a partir da mulher: uma nova hermenêutica, S. Paulo, Paulinas, 1992.

${ }^{8}$ SCOTT, Joan, "Gênero: uma categoria útil de análise histórica" em: Educação e Realidade, v. 10, n. 2, 1990, p. 5-22.
} 
dade $^{9}$. Basta citar como exemplo a lei de Lv 12,2-8, pela qual a mãe tornava-se impura por 40 dias após o parto quando o filho era um menino e o dobro do tempo quando era menina. Leis relativas à menstruação (Lv 15,19-24) e a hemorragias ( $\operatorname{Lv} 15,25-30)$ acentuavam a construção social negativa sobre a mulher.

2) Além disso, no nível simbólico, a linguagem bíblica sobre Deus é sempre usada no masculino. Isto confere ao homem, implicitamente, o poder de melhor refletir a imagem de Deus. Falar sobre Deus no feminino - em que pese a afirmação de Gn 1,27 - soa sempre estranho, mesmo hoje ${ }^{10}$.

3) Quanto à prostituição feminina, além das condenações sumárias e capitais da Lei (Dt 22,20s; Nm 5,11-31), havia toda uma simbologia, desenvolvida na literatura profética, associando a imagem da meretriz e da mulher adúltera ao povo idólatra e corrompido ${ }^{11}$.

4) Todos esses aspectos faziam parte do ambiente cultural da época de Jesus e exerciam influência no modo das pessoas se conceberem e conceberem os outros e outras na sociedade. Assim, na cabeça do fariseu Simão, a mulher que entrara em sua casa e se aproximara de Jesus, além de ser inferior "por natureza", era uma representante emblemática do pecado e da impureza. Daí o contraste com a expectativa de "santidade" em relação a Jesus que, se fosse realmente "profeta", deveria afastar-se da prostituta e não se deixar tocar/contaminar por ela.

E a mulher, como devia se sentir, vivendo dentro do mesmo ambiente? Certamente percebia-se como uma grande pecadora, por isso se colocara aos pés de Jesus, pois sentia-se envergonhada e indigna. Por isso também ela chorava copiosamente, ao ponto de banhar os pés de Jesus com suas lágrimas. Mas sua coragem em "furar" a multidão dos convivas (tratava-se de um banquete público) foi maior do que o medo e a vergonha de sua situação. Sua fé e seu amor ultrapassaram as barreiras socialmente impostas.

Quanto a Jesus, não deixou de ser educado e formado no mesmo quadro cultural e religioso e nas mesmas normas legais. Sua atitude, porém, foi de uma grande independência em relação aos padrões sociais. Deixou-se tocar e beijar pela mulher e ainda colocou-a como modelo para o fariseu! Mas voltaremos a este aspecto mais adiante.

9 Ver As discípulas de Jesus. Petrópolis, Vozes, 1990, 67-70.

${ }^{10}$ Elisabeth JOHNSON discute detalhadamente essa questão em seu livro Aquela que é. Petrópolis, Vozes, 1995.

11 Essa simbologia é inaugurada por Oséias e retomada por Isaías, Jeremias e outros, chegando a um grau exacerbado em Ezequiel (cf. Ez 16). 
5) Faz parte da cultura patriarcal criar dualismos, oposições e hierarquias. Aqui, o fariseu Simão se mostrou um representante dessa mentalidade. Pensava por oposições: pecadora x santo (profeta); e por hierarquias: provavelmente se considerava, enquanto autoridade (fariseu) mais importante do que seu convidado Jesus (suposto profeta), pois não lhe prestou as homenagens devidas de hospitalidade, conforme o costume da época (lavar os pés, ungir, beijar...). Em termos de hierarquia, havia uma escala simbólica entre o máximo da santidade, representado no caso pelo próprio fariseu, e o máximo da perdição, representado pela mulher pecadora. Jesus aparece, dentro daquela situação, como um personagem intermediário, que está sendo testado por seu anfitrião.

6) Uma última observação, relacionada ao gênero, é que o local onde se passa o episódio é ambíguo: por um lado, trata-se da casa de Simão, portanto um ambiente íntimo, doméstico (sempre associado ao feminino). Por outro lado, esse tipo de banquete era público ${ }^{12}$, tanto que as pessoas podiam entrar mesmo sem terem sido convidadas. Na realidade, a mulher atua como se fosse a "dona da casa", uma vez que ela desempenha o papel do anfitrião. Jesus, porém, vai se definir publicamente, e o faz defendendo a mulher e "desautorizando" completamente o anfitrião.

Assim, vimos que a construção cultural da sociedade em que se passa o episódio relatado por Lucas atingia igualmente os três personagens em questão; por outro lado, essa mesma construção social era re-significada por cada um dentro de sua própria perspectiva.

Ali transparecem as relações:

homem $\mathrm{x}$ mulher

$\mathrm{e}$

homem $\mathrm{x}$ homem

Só não aparece a relação mulher $\mathrm{x}$ mulher, que não vem à cena, mas que certamente estava ali presente, no mínimo como mão de obra indispensável (afinal, quem preparava os banquetes?).

C) Observações sobre a atitude dos três personagens no episódio

\section{1) A mulher}

Sobre ela é dito que era "da cidade" e "pecadora" (v.37). Seu nome não é mencionado, o que contrasta com a menção do nome do fariseu, uma vez que ela foi muito mais protagonista no episódio do que Simão. Não é dito explicitamente que era prostituta, mas há indícios claros disso: o fato, por

${ }^{12}$ Cf. JEREMIAS, J. As Parábolas de Jesus, São Paulo, Paulinas, 1978. 
exemplo, de enxugar os pés de Jesus com seus cabelos indica que a mulher soltou seus cabelos em público (as mulheres de família naquela sociedade cobriam sempre os cabelos ao sair de casa).

$\mathrm{O}$ fato de a mulher trazer "um vaso de alabastro cheio de perfume" (v.37) denota que ela gastou uma alta soma para comprá-lo (alabastro custava caro e provavelmente o perfume também), ou utilizou o presente de algum cliente rico. Tratava-se, qualquer que seja o caso, de um gesto de gratuidade, de manifestação inequívoca do grande valor que Jesus representava para ela. Mulheres e perfumes estão frequentemente associados não só na Bíblia (cf. Ct, Jt, Est) mas em muitas sociedades, inclusive a nossa. Esta associação também seria uma construção cultural? É provável, mas seria uma construção inofensiva. Nada contra. O perigo seria impedir o acesso dos homens a esse prazer. E não atentar para outros significados dos aromas e fragrâncias: perfume faz pensar em sedução, mas também em espiritualidade, em cura, em embalsamamento de mortos... quanta coisa mais?

$\mathrm{O}$ texto diz que a mulher veio porque soube, antes, que Jesus estava na casa do fariseu. Então ela já o conhecia ou já tinha uma opinião clara sobre ele ao decidir ir ao seu encontro. Já chegou sabendo muito bem o que ele significava para ela e manifestou por gestos inequívocos sua confissão de amor e de respeito. Pode-se comparar os gestos desta mulher com os da narração de Mc 14,3-9, onde outra (a mesma?) mulher anônima derrama perfume sobre a cabeça de Jesus ${ }^{13}$. Neste caso, o gesto podia ser interpretado como uma unção messiânica, uma confissão de fé no messianismo de Jesus. Mas no texto de Lc, trata-se antes de um gesto que não se deve separar de toda uma sucessão de gestos duas vezes mencionados no texto (vv. 37-38 e vv. 44-46):

- colocar-se por detrás, aos pés de Jesus

- banhar os pés dele com lágrimas

- enxugá-los com os cabelos

- cobri-los de beijos

- ungi-los com o perfume

Aqui era mais propriamente uma manifestação de carinho e amor, associado ao pedido de perdão. Pelo menos é assim que Jesus vai interpretar

${ }^{13}$ A relação do texto de Lc com o de Mc, que certamente foi uma de suas fontes, é discutida pelos autores. Mateus (26,6-13) e João (12,1-8) também narram o mesmo episódio, sendo que João identifica a mulher com Maria, irmã de Marta e Lázaro. O certo é que neste texto, a partir de certo ponto, a narrativa de Lc se afasta da de Mc e seus paralelos, tornando-se independente. 
aqueles gestos. Além disso, como já foi dito, tais gestos faziam parte do ritual de hospitalidade.

Assim como no episódio de Mc 14,3-9, a mulher não diz uma só palavra. Ela apenas age. E age com eloquência.

2) Simão, o fariseu

Este personagem é apresentado inicialmente como "um fariseu" que convidou Jesus a "comer com ele" (v.36). Este convite nos remete ao texto anterior, onde Jesus se queixa dos seus contemporâneos que o acusavam de comilão e beberrão, amigo de publicanos e pecadores (Lc 7,34). Embora Simão não se considerasse publicano nem pecador, admitiu convidar Jesus a partilhar de sua mesa, o que representa uma abertura em relação a outros colegas fariseus ${ }^{14}$.

No entanto, Simão não se mostra um bom anfitrião, já que ele deixa de cumprir o ritual de hospitalidade devido a Jesus (lavapés, ósculo da paz, unção com óleo perfumado). Ao contrário da mulher, ele se mostra reticente e indeciso: seria Jesus mesmo um profeta? Sua atitude ao convidar Jesus e não tratá-lo como de direito trai sua ambivalência, seu não comprometimento. É como aquele que põe a mão no arado e olha para trás (cf. Lc 9,62). Não se identifica com aquela boa medida, "socada, sacudida, transbordante" (cf. Lc 6,38) com que se deve julgar os outros e as outras. France QUÉRÉ chama-o de "homem do mínimo", e comenta:

"Os outros, para ele, não são hóspedes nem amigos. Diante de sua constante referência à Lei, só podem ser partidários ou adversários. É o que esmorece o relacionamento! Enquanto a pecadora deixa escorrer o perfume com abundância, ele, na sua preocupação de justiça, estanca todas as permutas. Não pode amar nem ser amado. Em dia com Deus, nada lhe deve"15.

Chama-nos a atenção aqui a mentalidade patriarcal que, como já vimos, estabelece oposições e hierarquias entre as pessoas. Neste ponto, Simão corresponde a esse perfil julgador: condenara de uma vez por todas a mulher e ficara à espera da reação de seu hóspede para classificá-lo: puro ou impuro; santo ou pecador; profeta ou impostor. Conforme o texto, o fariseu não ver-

\footnotetext{
${ }^{14}$ Lembremos de que, no momento da redação de Lc, a comunhão de mesa entre cristãos vindos do judaísmo e os de origem pagã era um problema importante nas comunidades. Disto nos dão notícia os Atos dos Apóstolos. Um judeu devoto jamais se sentaria à mesa com um conviva impuro.

15 QUÉRÉ, F., As mulheres do Evangelho. S. Paulo, Paulinas, 1984, 99.
} 
balizou seus pensamentos, mas deixou-os transparecer de algum modo, tanto que Jesus captou...

3) Jesus

Lucas mostra-nos Jesus entrando na casa do fariseu e assumindo sem rodeios sua posição de convidado: "e recostou-se à mesa" (v. 36) ${ }^{16}$. Quando a mulher entra, ele a deixa agir, aparentemente sem constrangimento algum. Não interrompe sua iniciativa, não apresenta reservas aos seus gestos, apenas permite que ela se expresse, ainda que isto pudesse comprometê-lo, pois contrariava os padrões de pureza e a moral de sua sociedade. Ao mesmo tempo, observa a fisionomia e as reações do fariseu. Ciente dos pensamentos de Simão, o Jesus de Lc vai argumentar com seu anfitrião.

Sua argumentação se faz em dois passos:

1. vv. 40-43: partindo da psicologia do fariseu, que gosta de apontar o pecado dos outros, e que aprecia o recurso a parábolas nos debates intelectuais, Jesus propõe uma parábola. O tema é a questão da dívida (= pecado). Mas acrescenta-se aqui o aspecto do "tamanho da dívida". Ótimo: a ideologia patriarcal se identifica com hierarquizações e classificações. Só que o feitiço vai se virar contra o feiticeiro. Ao introduzir a questão do "tamanho' ou do "grau" do pecado, Jesus lembra implicitamente que o fariseu também é pecador. Apenas sua "dívida" seria supostamente menor do que a da mulher. De fato, esquematicamente a progressão do raciocínio na parábola contada por Jesus é a seguinte:

dívida maior--------> perdão maior -----------> amor maior

subentendido:

dívida menor ---------> perdão menor ----------> amor menor

Assim, Jesus parte do pecado e desemboca no amor, passando pelo perdão. E no final pede que o próprio fariseu dê a conclusão da parábola: "Qual dos dois o amará mais?" (v. 42). Constrangido, Simão responde: "Penso que aquele a quem ele perdoou a maior divida" (v. 43). Uma vez chegado a este ponto, Jesus vai poder continuar sua argumentação não mais no terreno do fariseu - o terreno das prescrições legais, das disposições penais (sistema patriarcal) - mas a partir de um outro espaço: o espaço das relações de amor.

${ }^{16}$ Nas refeições solenes da época, os convivas se recostavam em divãs para comer. 
2. vv. 44-46: Aqui Jesus se volta para a mulher e a re-apresenta a Simão. Ele vai responder à pergunta inconfessada do fariseu apresentando-lhe uma nova e insuspeitável mestra. Ao mesmo tempo, vai deixar claro ao seu interlocutor (bem como aos outros convivas presentes) o que significa para ele ser PROFETA. Agora não utiliza mais parábolas. Parte de fatos concretos. Descreve um por um os gestos da mulher, não sem ter o cuidado de dizer antes o que seu anfitrião deixou de fazer: "tu não me derramaste água sobre os pés.... não me beijaste.... não me derramaste óleo perfumado....". O contraste entre a omissão do fariseu e a generosidade da mulher fica cada vez mais patente. Como interpreta Jesus os gestos da "pecadora"? Como manifestação de AMOR. E conclui: "Por essa razão, eu te digo: seus numerosos pecados lhe estão perdoados porque ela demonstrou muito amor" (v. 47a) ${ }^{17}$. O esquema, então, se inverteu: partindo do amor, chega-se ao perdão:

amor maior -----------> perdão maior

subentendido:

amor menor -------------> perdão menor

O pecado desaparece da argumentação, a não ser enquanto subentendido no ato do perdão.

Após terminar sua conversa com o fariseu, Jesus dirige-se à mulher: “teus pecados estão perdoados... tua fé te salvou, vai em paz" (vv. 48 e 50). Como em outros textos de perdão e cura, essas palavras dão a entender que a mulher em questão estava totalmente restabelecida em sua dignidade e passava a ser admitida na comunidade dos seguidores e seguidoras de Jesus. Somente aqui no final aparecem os outros convivas, surpresos: "Quem é este, que até perdoa pecados?" (v. 49). Volta então a pergunta do início sobre a identidade de Jesus.

\section{Conclusão}

Nesta rápida tentativa de abordagem de gênero alguns pontos puderam ser observados, outros ficarão para novas aproximações e precisões ou correções. Do conjunto deste texto, depreende-se que tanto a mulher como Jesus transgrediram certos padrões sociais, legais e religiosos de sua sociedade. $\mathrm{O}$

${ }^{17} \mathrm{O}$ versículo 47 é problemático, pois vem constituído de forma dupla: a primeira parte responde ao tema da narrativa: “... seus numerosos pecados lhe estão perdoados porque (em grego "hoti”) ela demonstrou muito amor". A $2^{\mathrm{a}}$. parte do versículo 47 responde à parábola, portanto volta atrás na argumentação: “aquele a quem pouco foi perdoado, mostra pouco amor". Sobre esta questão, ver meu artigo "Jesus, the penitent woman...", p.33-34. 
texto em si já rompe com qualquer classificação rigorosa dos papéis masculinos e femininos, pois:

- o local onde se passa o episódio - e onde Jesus se revela como profeta - é ao mesmo tempo privado (casa do fariseu) e público (banquete solene). É um espaço masculino e ao mesmo tempo feminino. O público e o privado perdem suas fronteiras e cedem lugar ao espaço das relações humanas;

- o ritual de hospitalidade é "roubado" ao dono da casa por uma estranha. Pelo gesto do lavapés, que era uma atribuição de escravos, a mulher manifesta sua liberdade, porque ela está expressando seus sentimentos; o ritual é re-significado em linguagem amorosa, para além das convenções sociais;

- a dinâmica do julgamento e das classificações condenatórias cede lugar à dinâmica do dom, da gratuidade, da reciprocidade. Ao invés de ser condenada e excluída, como imaginava o fariseu, a mulher é reconhecida, respeitada e acolhida por Jesus, assim como ela própria o acolhera, ainda que em casa estranha. Nesta dinâmica, não importam os papéis sociais, institucionais. Não se trata de definir o que é próprio do feminino ou do masculino. Importam as relações sinceras de amor entre pessoas humanas, todas chamadas a serem livres e felizes no tempo que lhes é dado viver.

Retomando, então, a pergunta inicial sobre a busca de uma nova identidade: descobriremos e construiremos nossa identidade na medida em que soubermos re-significar nossas tradições de tal modo que possamos re-ativar (e não repetir ou imitar) em nossa sociedade a criatividade que Jesus, a "mulher do perfume" e os primeiros cristãos e cristãs tiveram na sua própria sociedade.

O texto estudado à luz do gênero aponta para uma novidade que apareceu na atitude da mulher e de Jesus. Trata-se de um modo de ser que liberta e abre para o amor, passando pela des-construção de tudo aquilo que é criação humana e que pode ser mudado, contanto que garanta a livre circulação do amor.

Tereza Maria Pompéia Cavalcanti

Professora do Departamento de Teologia da PUC-Rio Doutora em Teologia e Licenciada em Psicologia pela PUC-Rio 